\title{
PALACIO DE CONGRESOS Y EXPOSICIONES DE GALICIA EN SANTIAGO (GALICIA, ESPAÑA)
}

\author{
(CONGRESS AND EXHIBITION PALACE OF GALICIA IN SANTIAGO. GALICIA, SPAIN)
}

Alberto Noguerol del Río, Arquitecto y Pilar Diez Vázquez

ESPAÑA

Fecha de recepción: 28-VII-95

\section{RESUMEN}

El Palacio de Congresos y Exposiciones de Galicia es una gran sala en la que pueden celebrarse diversos actos a la vez. Se detallan, de manera explicita, todos los elementos constructivos que han formado parte de la obra, desde los más elementales hasta su estructura, haciendo especial mención de todos los detalles que la complementan.

\section{SUMMARY}

The Congress and Exhibition Palace of Galicia is a large hall in which various different events can be held at a time. All construction elements are given explicitely and in detail, from the most basic ones to the structure, paying special attention to the complementary details.

El lugar, alejado del casco urbano, era entre monte bajo y rural, cercano al nudo de comunicación que conecta la ciudad con su aeropuerto y con la autopista que une La Coruña con Vigo, carecía de la cualidad que hace que un proyecto nazca acorde con su emplazamiento. Sólo nos ofrecía la presencia del monte cercano. La posición, el tamaño, la entrada, todo debería surgir de esa presencia.

El programa, con la imprecisión deseable, fijaba como necesaria una gran sala que permitiese la celebración de conciertos y la flexibilidad necesaria para admitir dos congresos simultáneos. El resto, lo previsible.
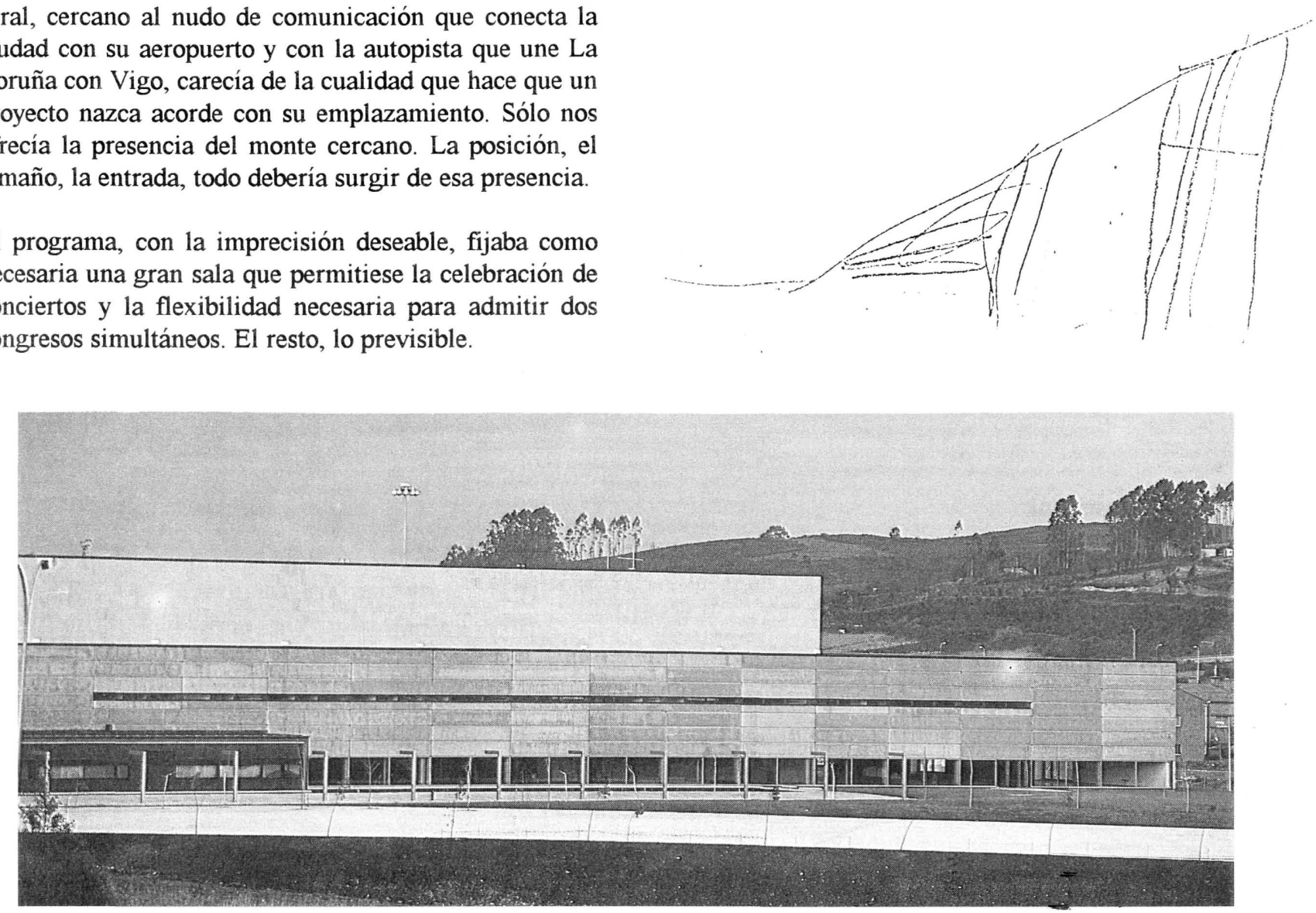


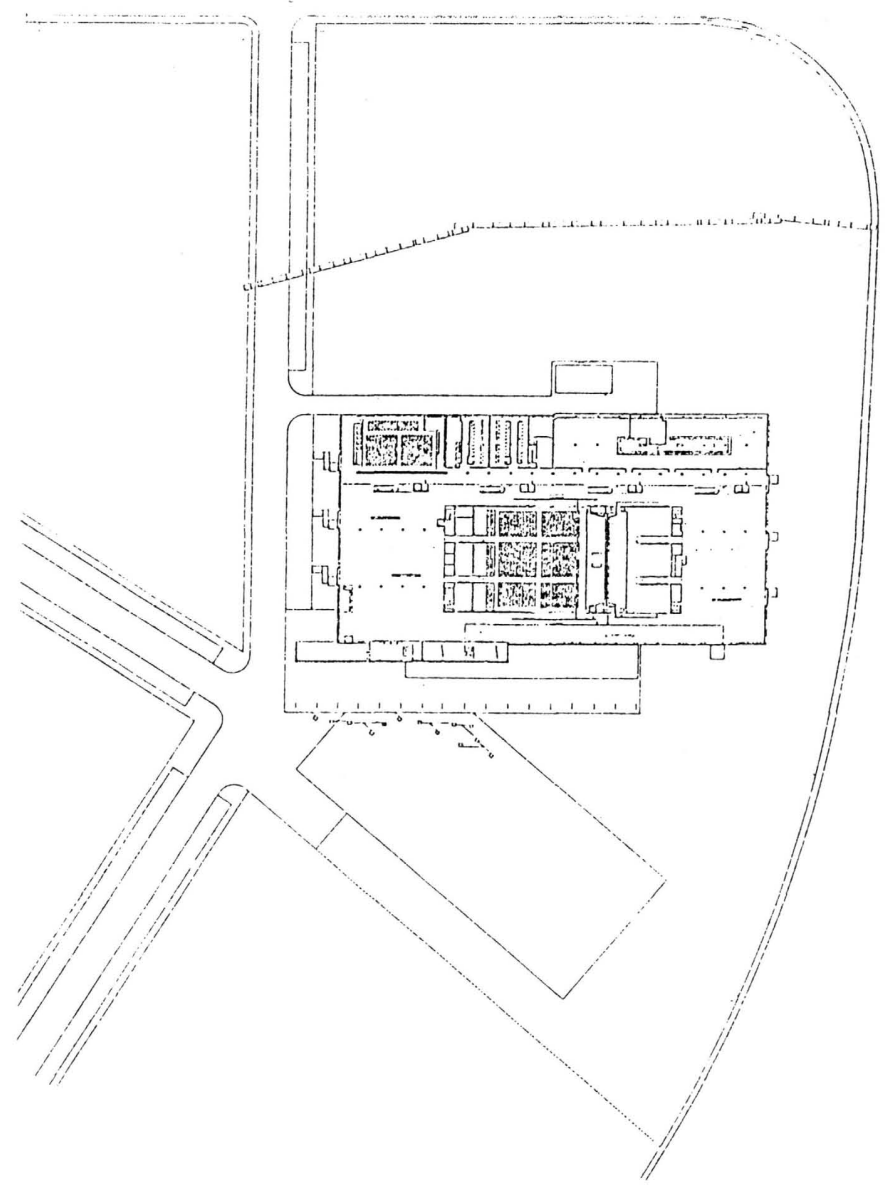

Emplazamiento.

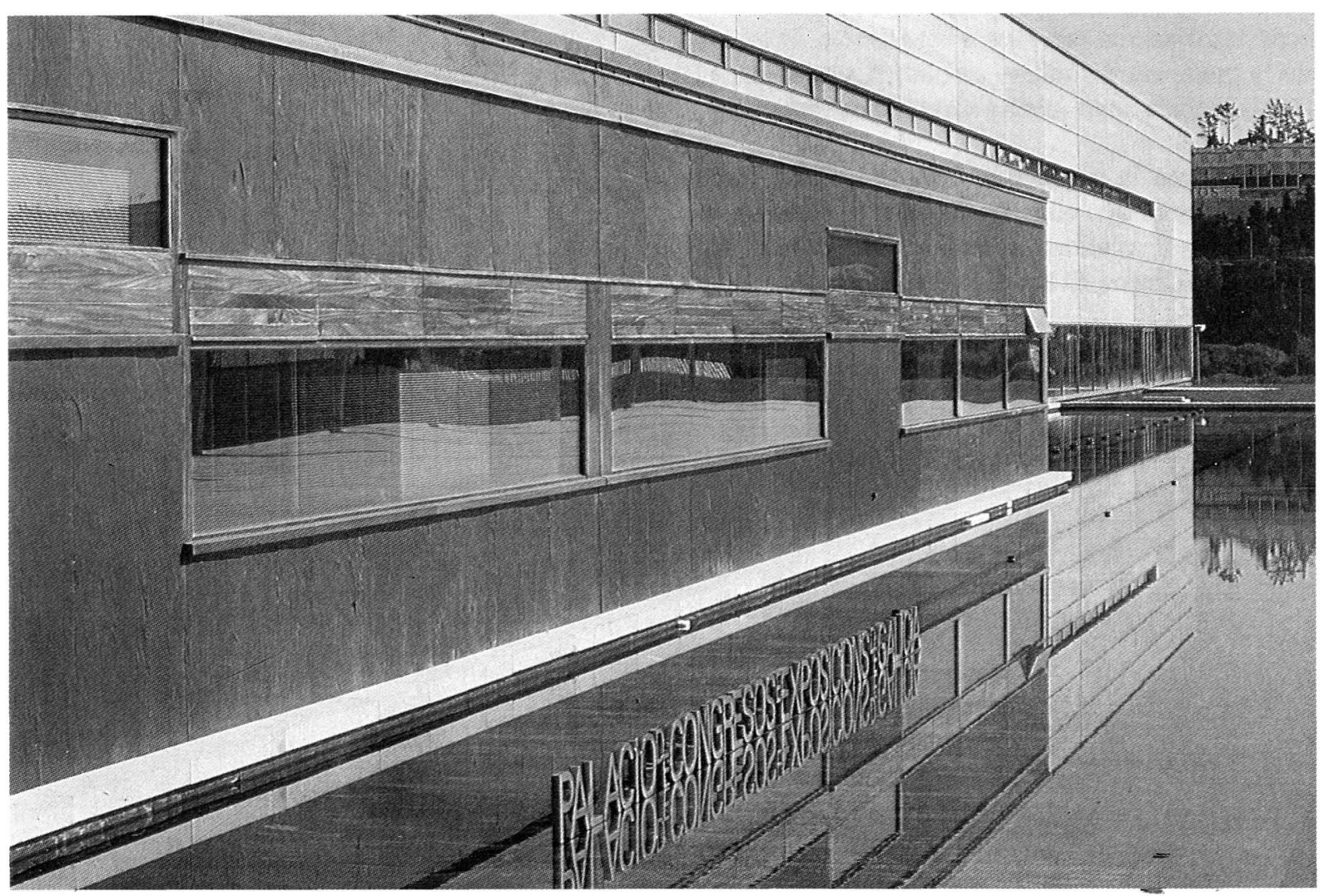

El estanque ante el cuerpo de administración.

(c) Consejo Superior de Investigaciones Científicas Licencia Creative Commons 3.0 España (by-nc) http://informesdelaconstruccion.revistas.csic.es 


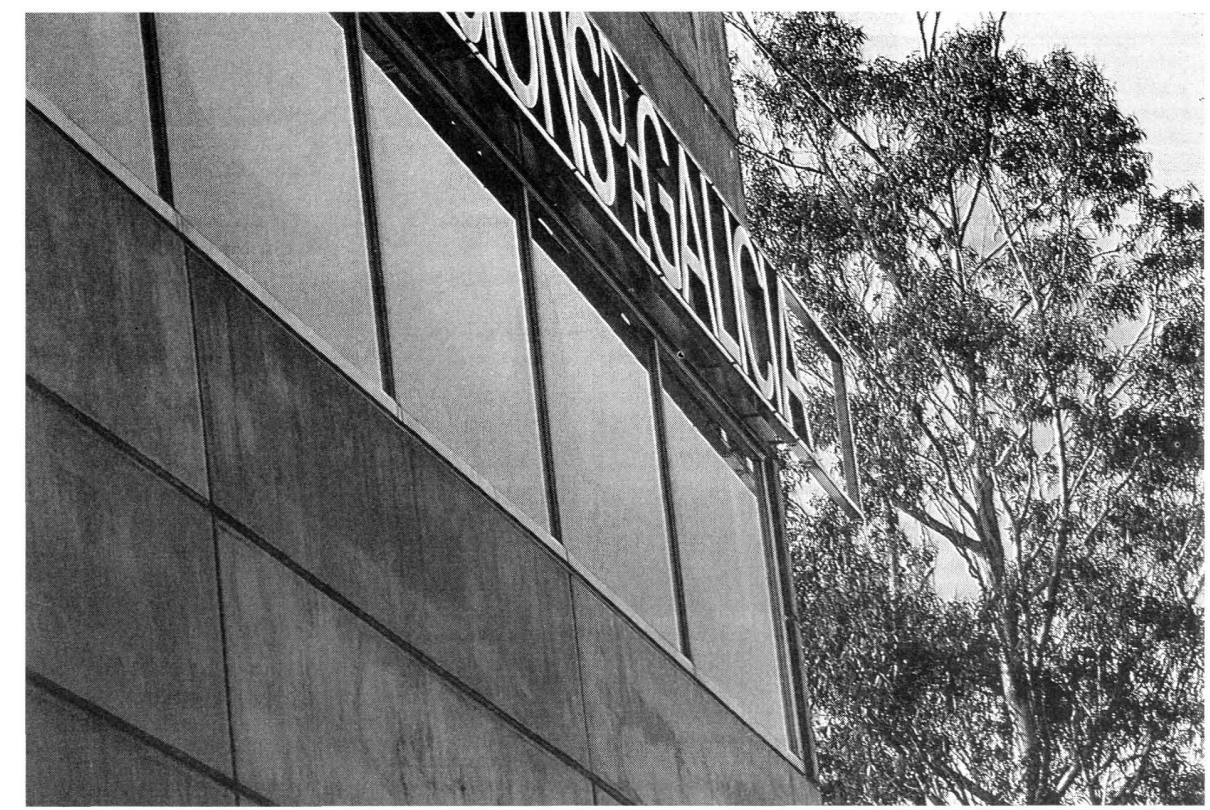

El rótulo mayor de la cara Norte.

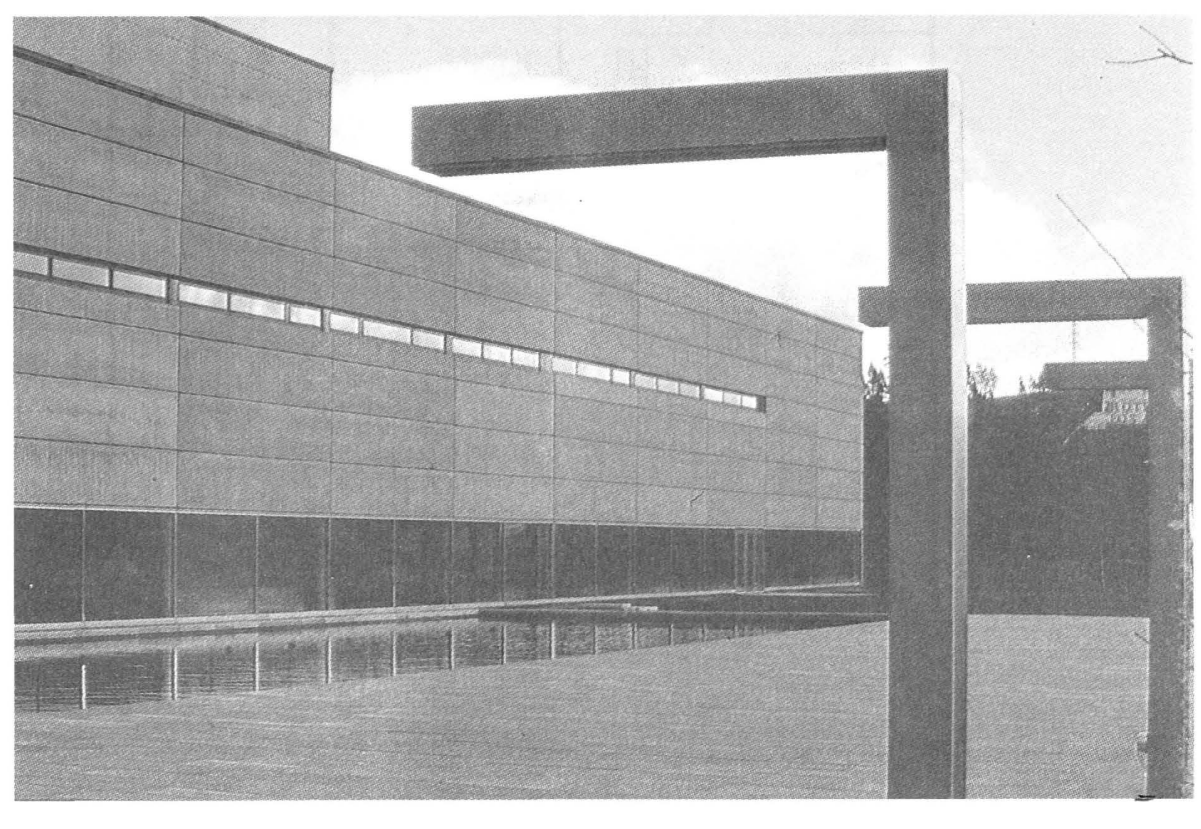

Las luminarias de la plaza de acceso.

(c) Consejo Superior de Investigaciones Científicas Licencia Creative Commons 3.0 España (by-nc) 


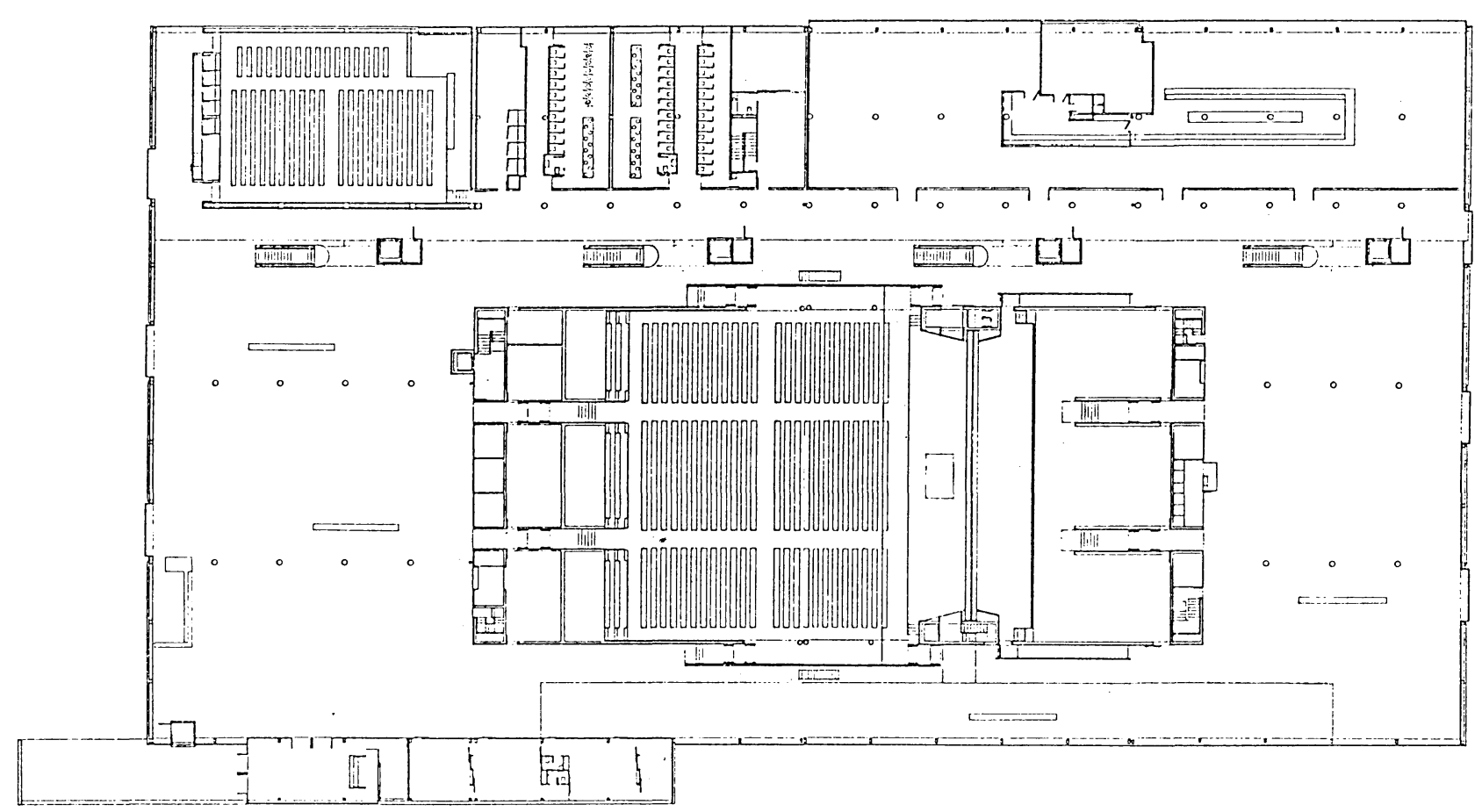

Planta 0.

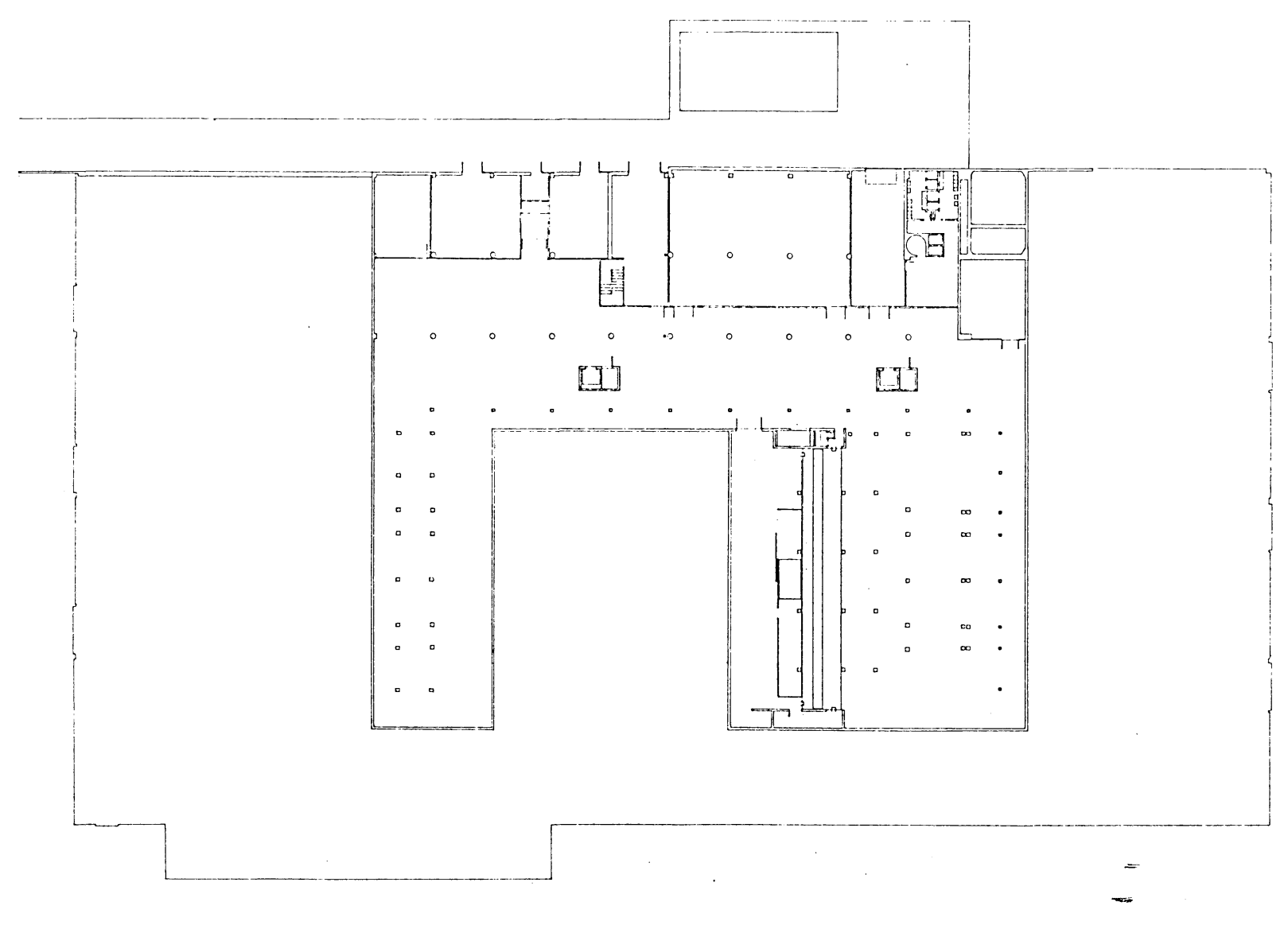




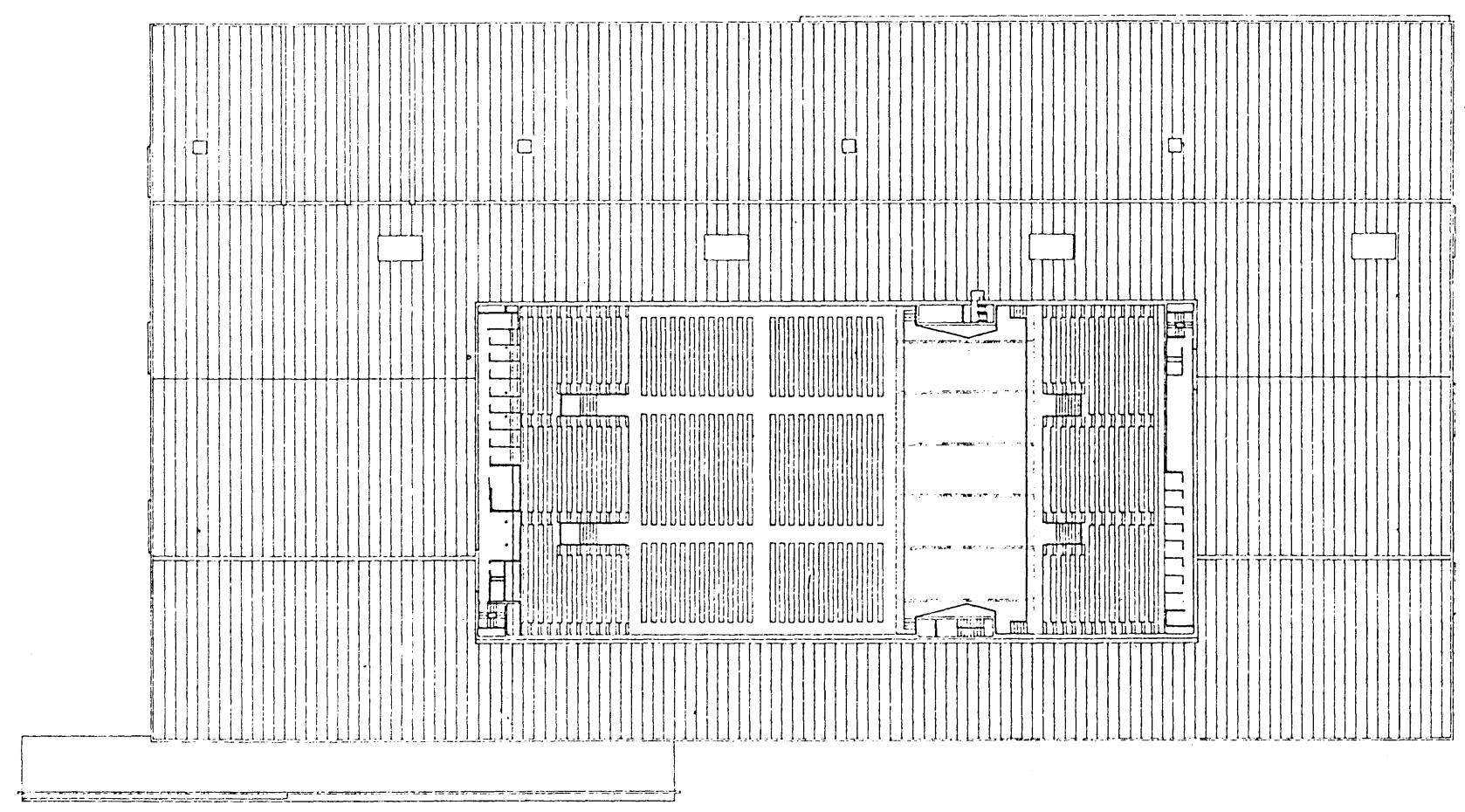

Planta 2

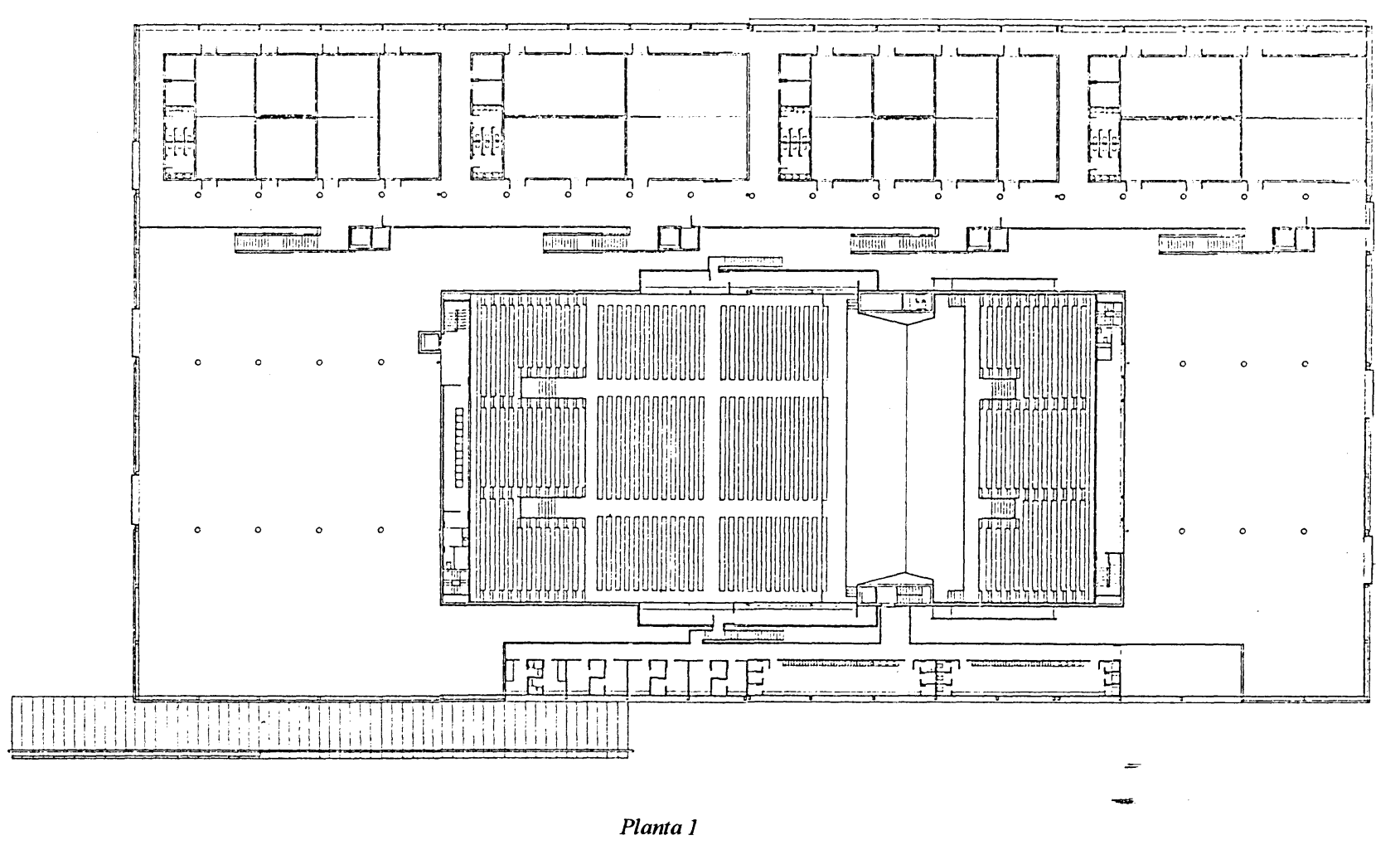


El presupuesto, ajustado, debía permitir construir un edificio austero pero acogedor y versátil, de aspecto lejano a otros de uso familiar.

La planta, un rectángulo de $65 \times 120 \mathrm{~m}$, contiene en su cara Norte la casi totalidad de lo necesario. La gran sala, otro rectángulo de $31 \times 67 \mathrm{~m}$, contenido dentro del anterior y emergiendo sobre su cubierta. La entrada y administración son como un cuerpo alargado y estrecho, adosado a la fachada Sur. Los camerinos, colgados en el espacio que une los dos grandes vestíbulos.

Una gran plaza y un estanque a la entrada. Una superficie pavimentada como parking ocasional y lugar para instalar exposiciones. En la fachada Norte, una calle de servicio da acceso a las dependencias del sótano y se ensancha para dar cabida a la maquinaria del aire acondicionado. Alrededor de todo, la vegetación, mitigará la excesiva presencia de la vía rápida cercana, aparecida cuandoel edificio se construía.
Las secciones evidencian lo inmediato de la composición: dos paralelepípedos.

Las fachadas, de dos materiales, prefabricado de hormigón para el cuerpo grande y bajo, y granito para el pequeño y alto... "pensaré en esto"....Pizarra y madera en lugares concretos y carpintería de acero inoxidable. Los paneles, teñidos de un casi imperceptible color gris, mejoran al mojarse con la lluvia. El granito silvestre, montado con soportes de acero inoxidable, con cámara ventilada. Cubiertas de chapa de cobre, pavimentos exteriores de granito en la plaza de acceso y de prefabricado de hormigón en la acera ancha que discurre ante la fachada Oeste.

En el interior, de piedra San Vicente en vestíbulos y resto de planta baja; en la zona de aulas, terrazo micrograno negro. En camerinos linóleo y, en las salas, entarimado de roble.

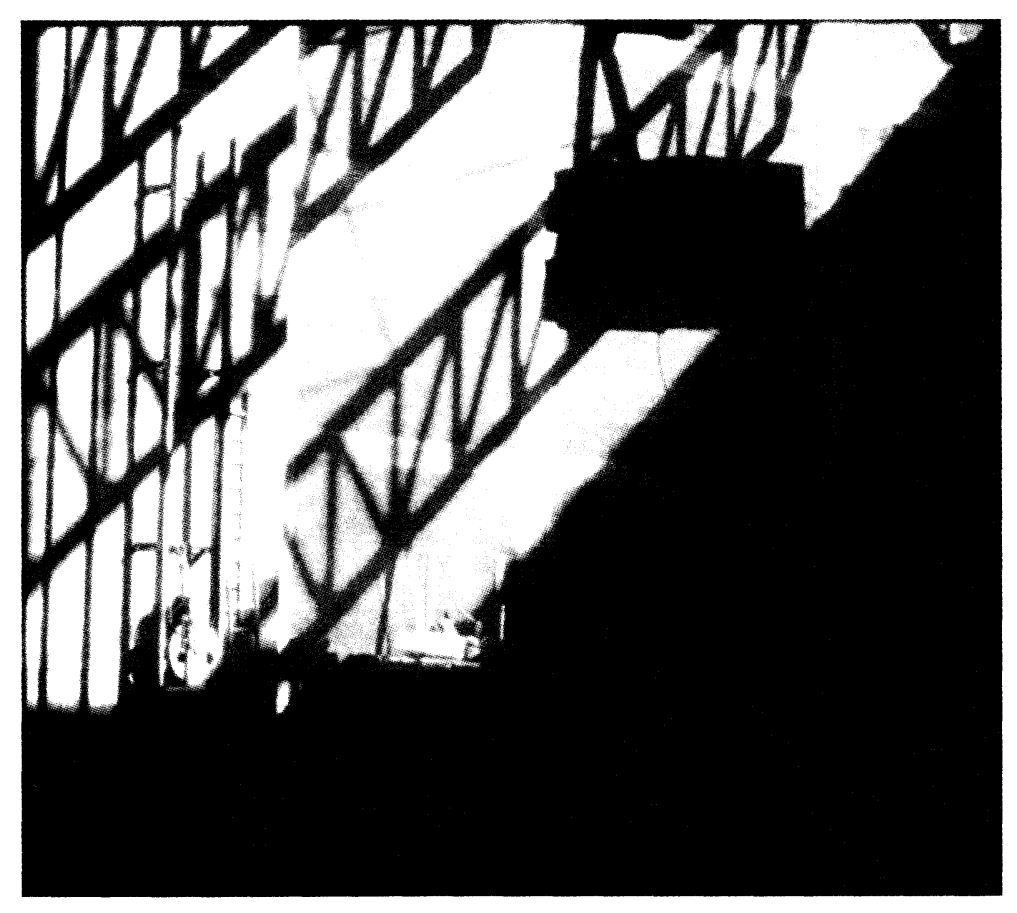

La sala principal durante la obra.

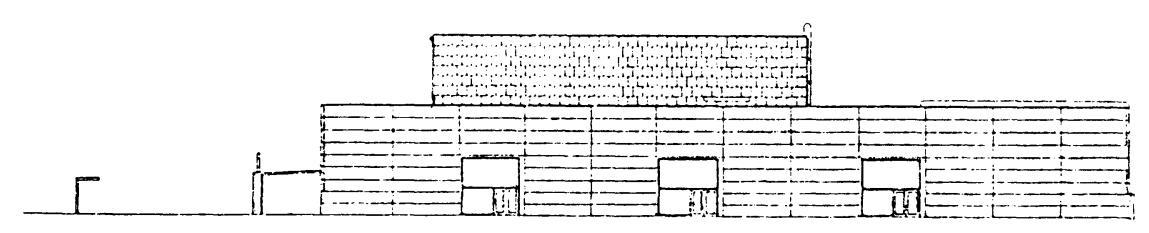

Alzado Este. 
Falsos techos de celosía de aluminio en vestíbulos, de tablero chapeado de mansonia o caoba en salas y administración, y de escayola lisa en el resto.

Paredes interiores de granito, fabrica de ladrillo, revoco y pintura, tablero chapeado o tablero esmaltado, según las zonas.

La sala principal, bifocal, con capacidad para 2.100 personas, puede ser dividida en una para 1.600 y en otra para 500 plazas, accionando un gran telón hidráulico que, alojado en el sótano, se alza a través de una grieta abierta a lo largo del escenario y produce el aislamiento necesario para el uso simultáneo de las dos salas resultantes.

El escenario, de $310 \mathrm{~m}^{2}$, cuenta con una plataforma hidráulica para el piano. Un montacargas y un ascensor comunican el escenariocon el sótanoy camerinos respectivamente. Dos grietas en los laterales de piedra, son los palcos para prensa o invitados. En el fondo, el palcode autoridades $y$, sobre él y en el otro fondo, las cabinas de traducción simultánea y proyección.

La sala menor, para 400 plazas, se sitúa en la misma banda Norte que la sala de prensa, aseos generales, sala de autoridades y cafetería, haciendo de fondo a los vestíbulos. Cuatro grupos de escalera y ascensor dan acceso, en esa misma banda, a la planta superior, en la que se sitúan cuatro grupos de salas de forma y superficie variable, despachos y aseos, todo ello servido por un gran corredor hacia los vestíbulos y una galería hacia la fachada.

En el sótano, almacenes, vestuarios, instalaciones, el foso del telón, etc.

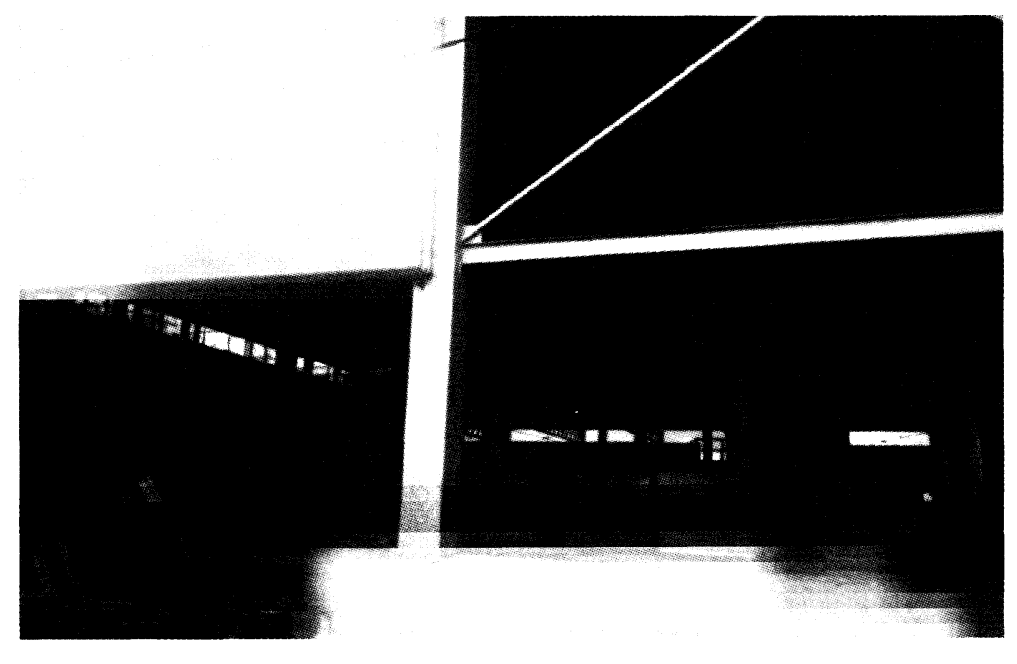

La constucción del cerramiento.

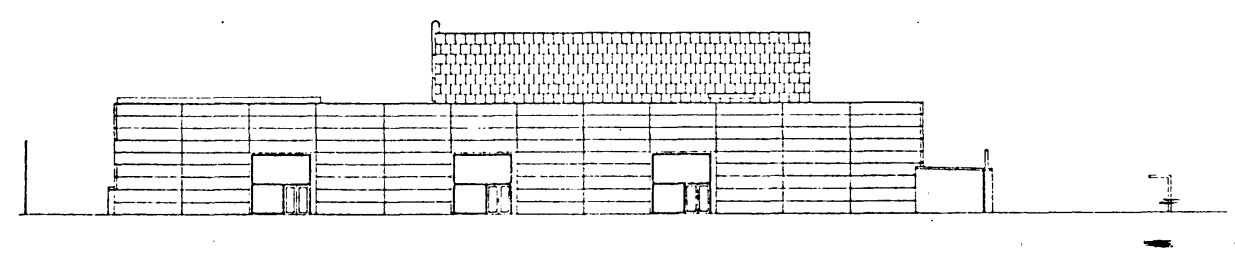

Alzado Oeste. 


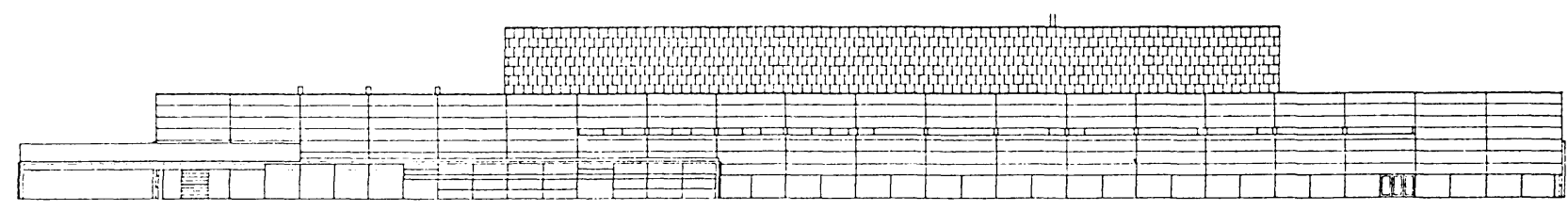

Alzado Sur.

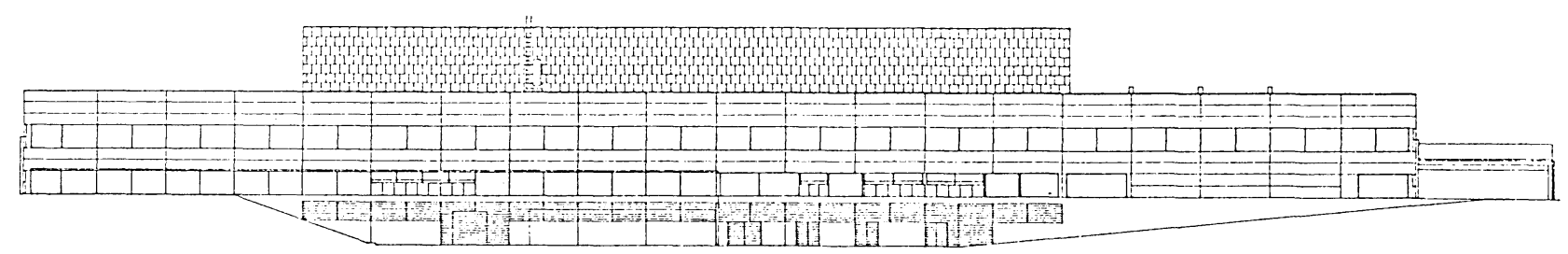

Alzado Norte.

La estructura, sobre pilotaje, de pilares y vigas de hormigón y acero, forjado convencional en suelos de planta baja, de vigas pi en planta 1 y de siporex en cubiertas. Cerchas metálicas de luz $30 \mathrm{~m}$ y canto $2,60 \mathrm{~m}$ para cubrir la sala.

Aire acondicionado en todo el edificio, con solución especial para la sala principal, en donde la impulsión se produce desde la cámara bajo el forjado del suelo hacia un plenum entre forjadoy pavimento, con velocidad de $0,2 \mathrm{~m} / \mathrm{s}$, siendo la extracción a través de las grietas del falso techo que, también, albergan la iluminación. En la sala de 400 plazas, la impulsión se produce desde el techo, siendo el retorno a través de dos finas grietas hechas en los laterales.

Las luces de emergencia de escaleras y gradas de la gran sala, con fibra óptica, lo que permite resolver el problema con una pequeña perforación de $2 \mathrm{~mm}$ de diámetro.

Las torres de los ascensores y la barra de la cafetería, de mármol negro de Grecia, que hace menos evidente su presencia. En el mostrador de információn, ónice de Pakistán, para lograr lo contrario. 

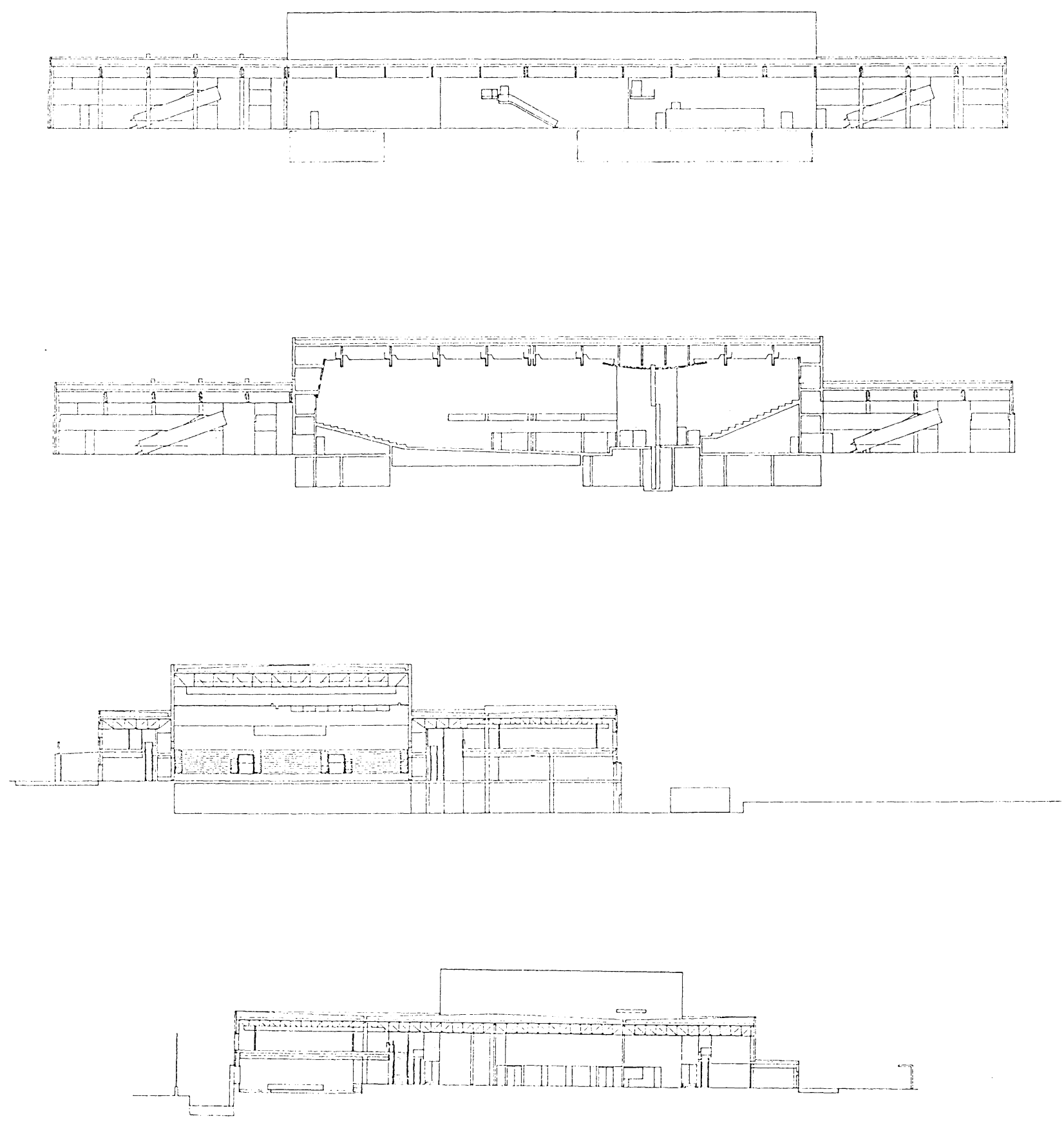

Secciones.

En la sala principal, butacas de acero, madera y terciopelo; en la menor, butacas de acero y piel, ambas, diseño de los autores y fabricadas especialmente para esta obra.

Rótulos exteriores de acero inoxidable. Junto a muebles de Le Corbusier, Mies, Breuer, Stam, Jacobsen, Takahama, Scarpa, Kjaerholm, Eames, etc., otros de los autores, diseñados expresamente para la ocasión, entre ellos, una mesa auxiliar para la sala de autoridades, las mesitas de acero y cristal para la administración, las banquetas para camerinos y locutorio y las sillas para cafetería, restaurante, escenario y salas, fabricadas bajo diseño de los autores con el nombre de silla $\mathrm{L}$.

Dos alfombras, también nuestras, para la sala de autoridades. 


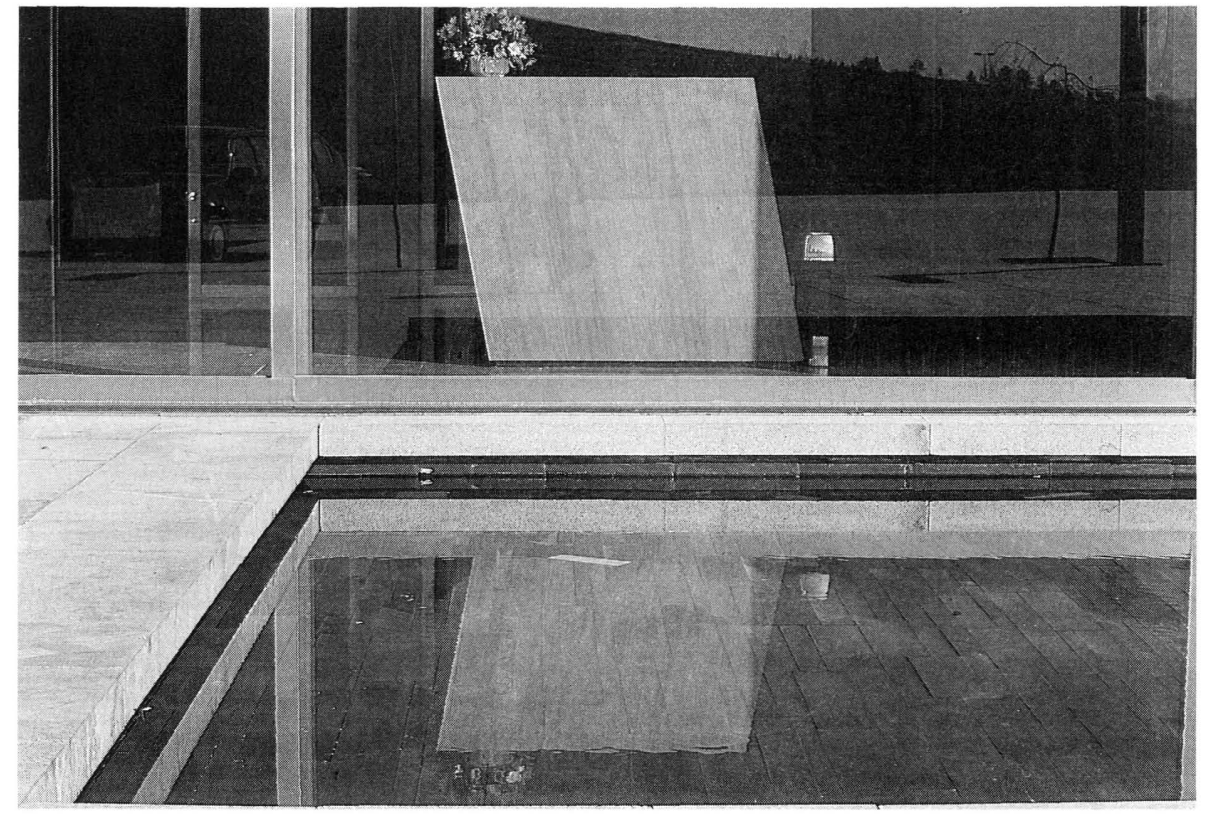

El mostrador del control de acceso.

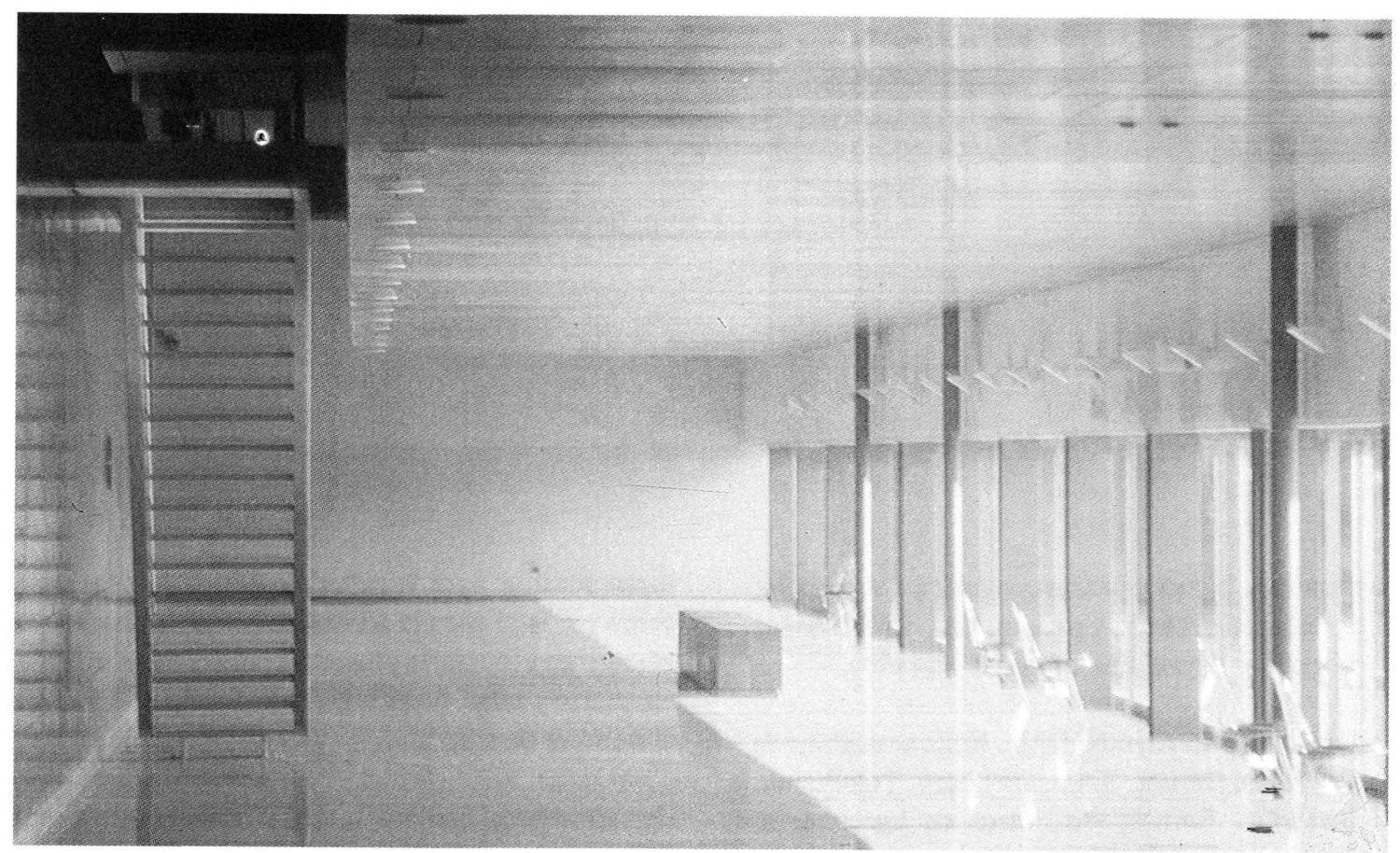

El cuerpo de los camerinos colgado entre los dos vestibulos.

(c) Consejo Superior de Investigaciones Científicas 


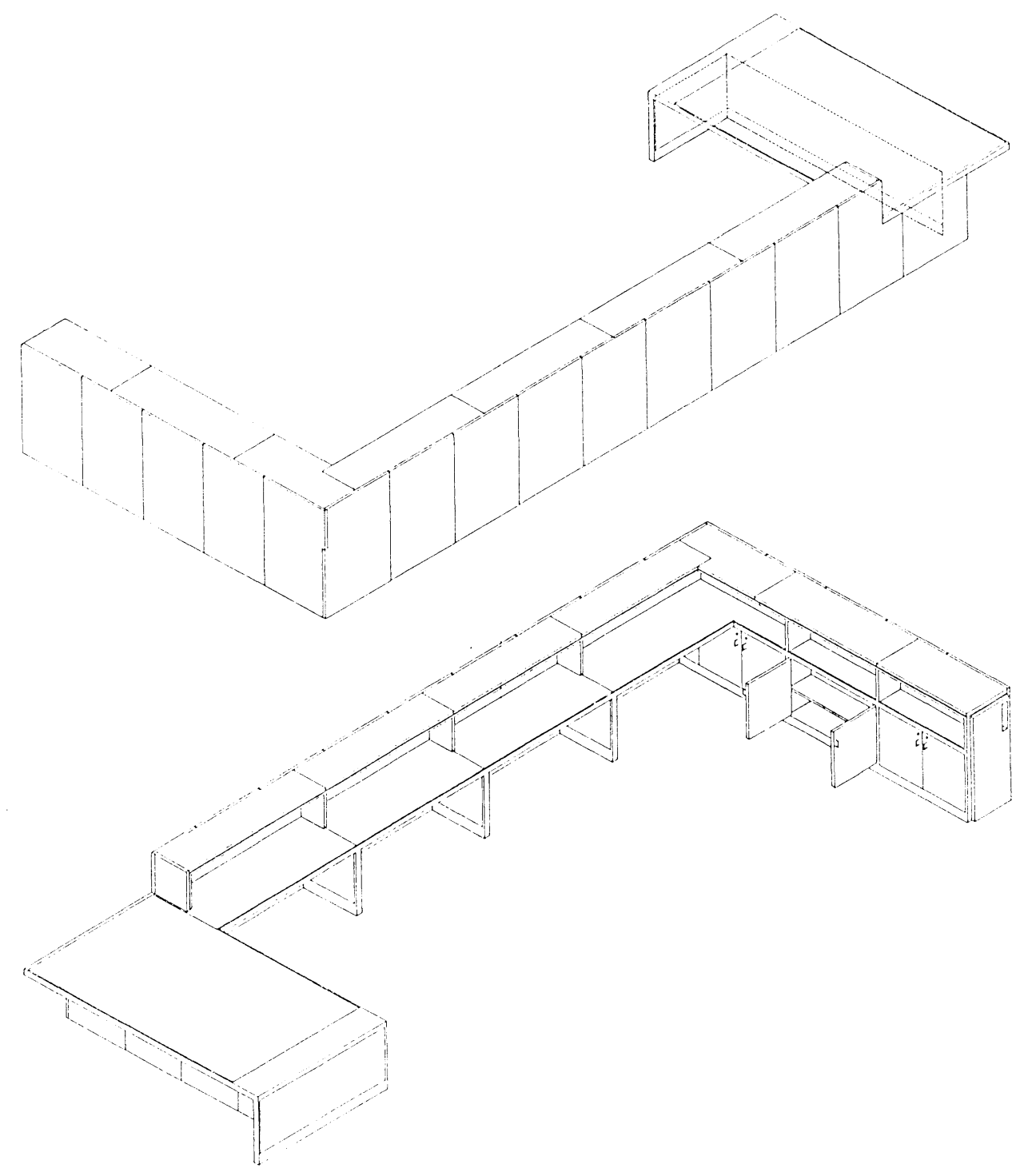

El mostrador de información. Onice sobre tablero chapeado.
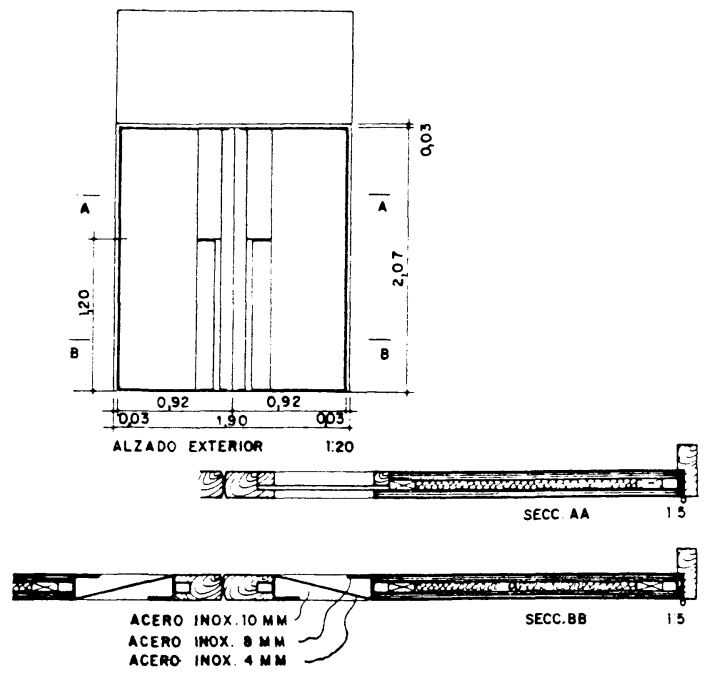

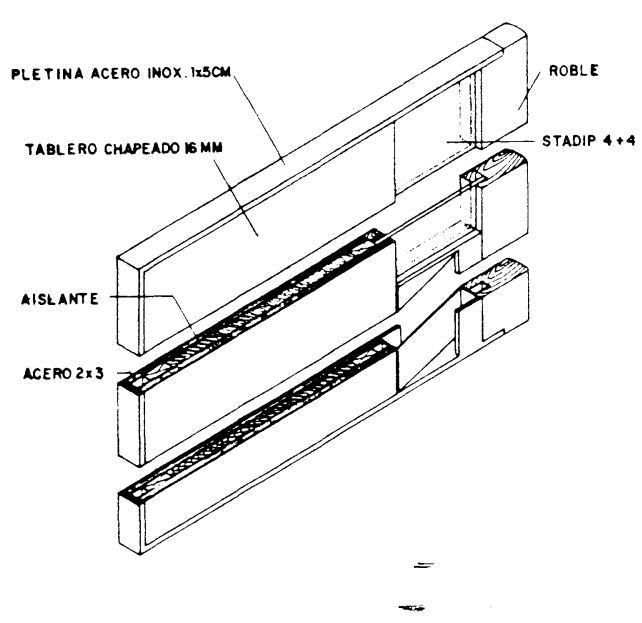

Puerta de las salas.

(c) Consejo Superior de Investigaciones Científicas Licencia Creative Commons 3.0 España (by-nc) 


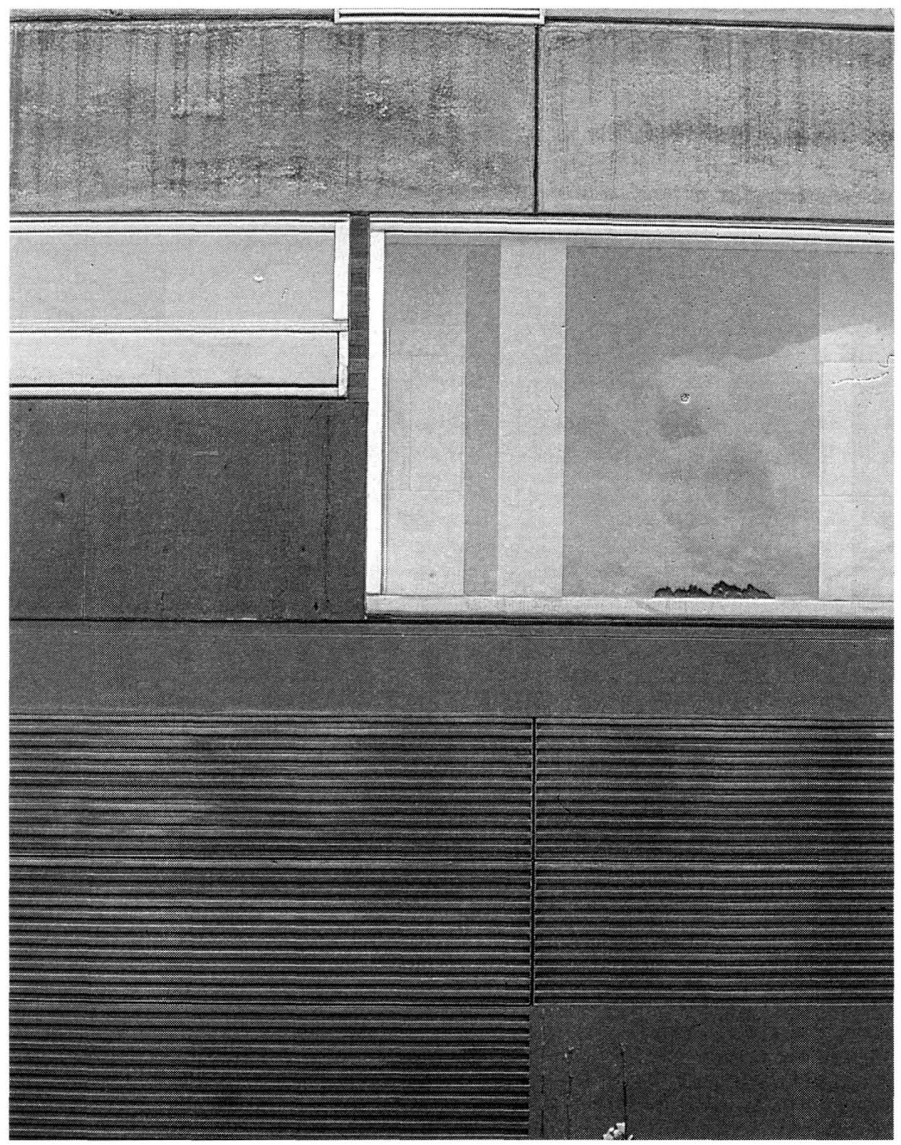

Detalle del alzado Norte.
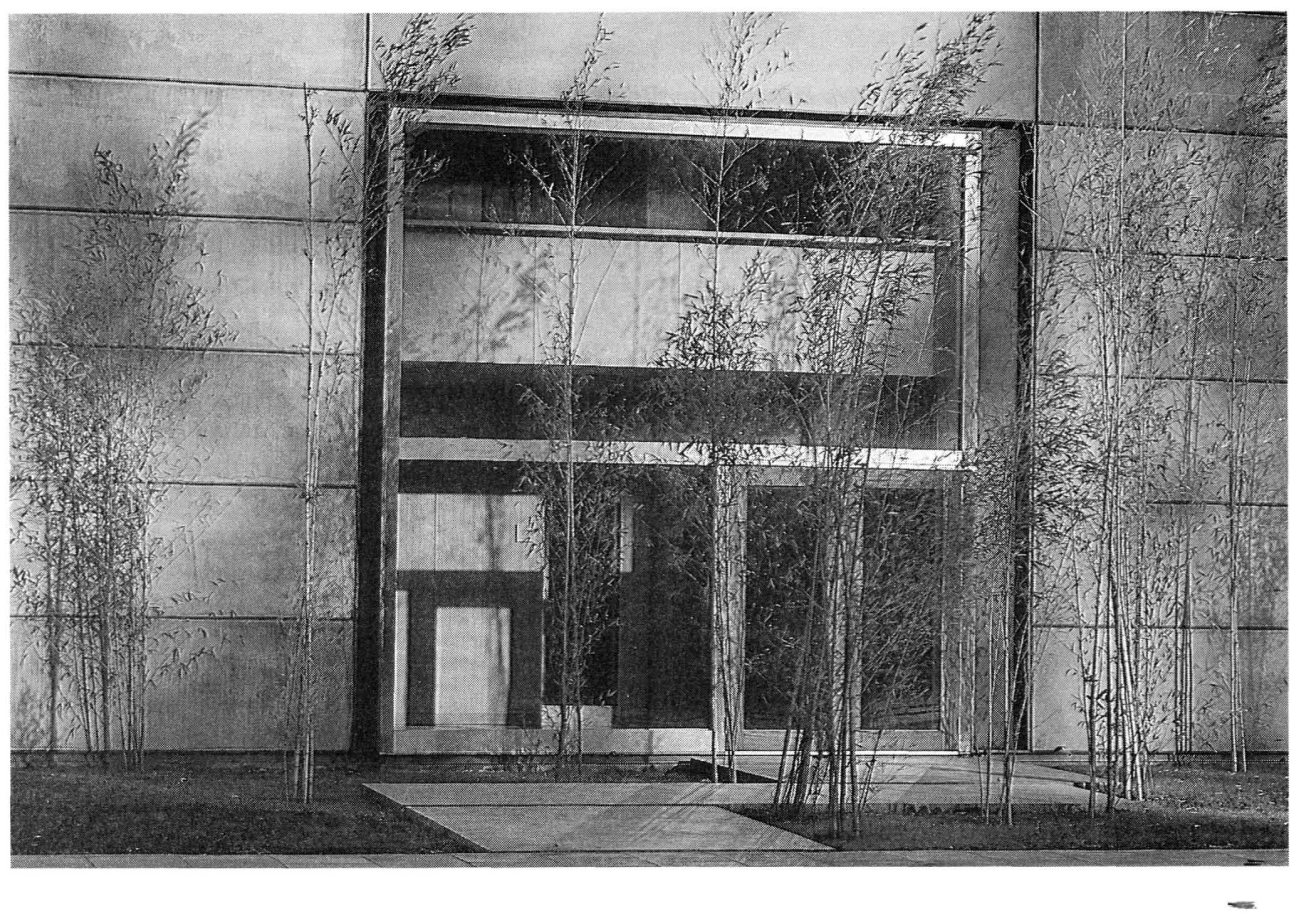

Puerta de emergencia en la cara Oeste.

(c) Consejo Superior de Investigaciones Científicas 
Informes de la Construcción, Vol. 47 n 439, septiembre/octubre 1995
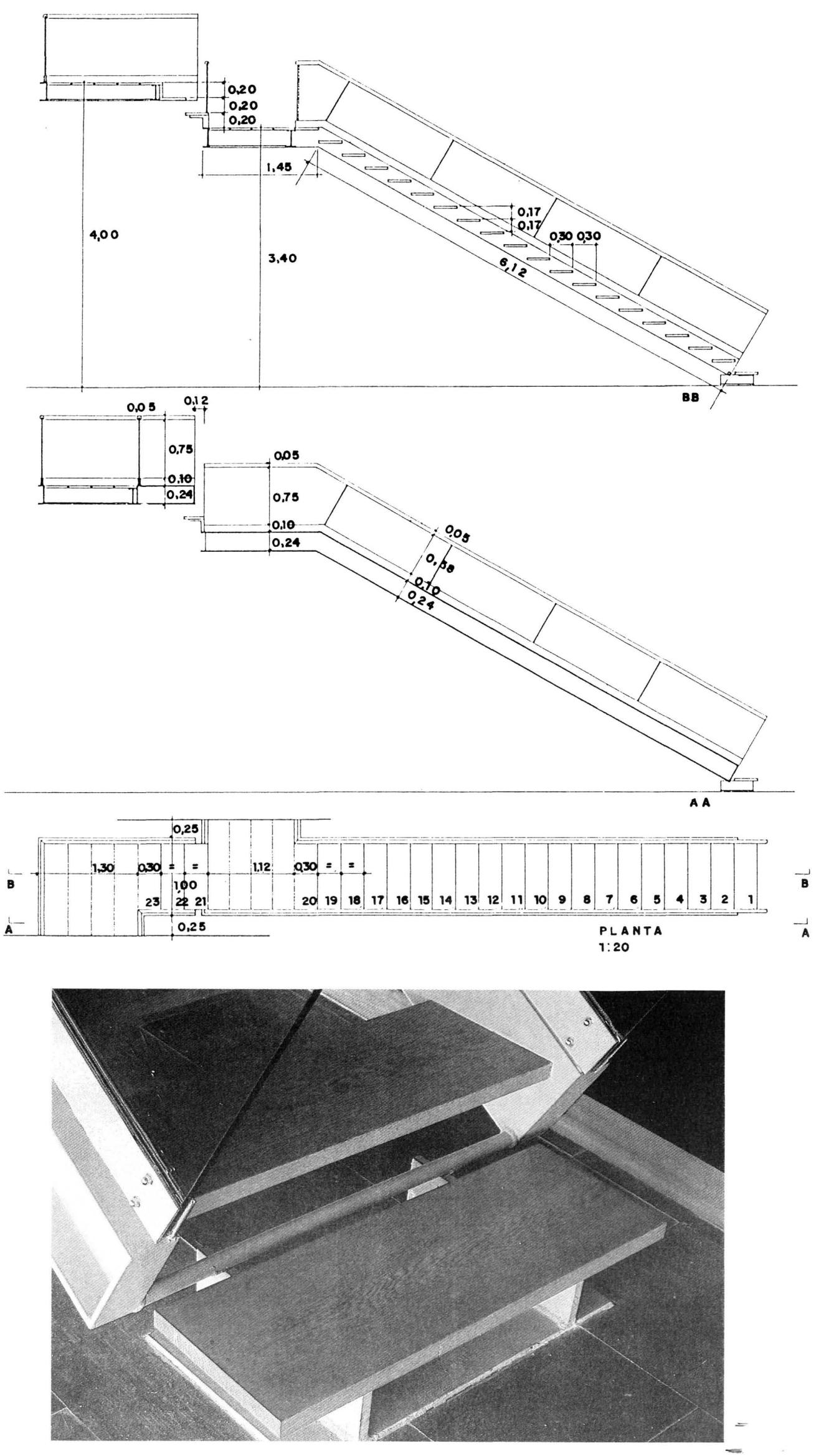

El arranque de la escalera de camerinos.

(c) Consejo Superior de Investigaciones Científicas 

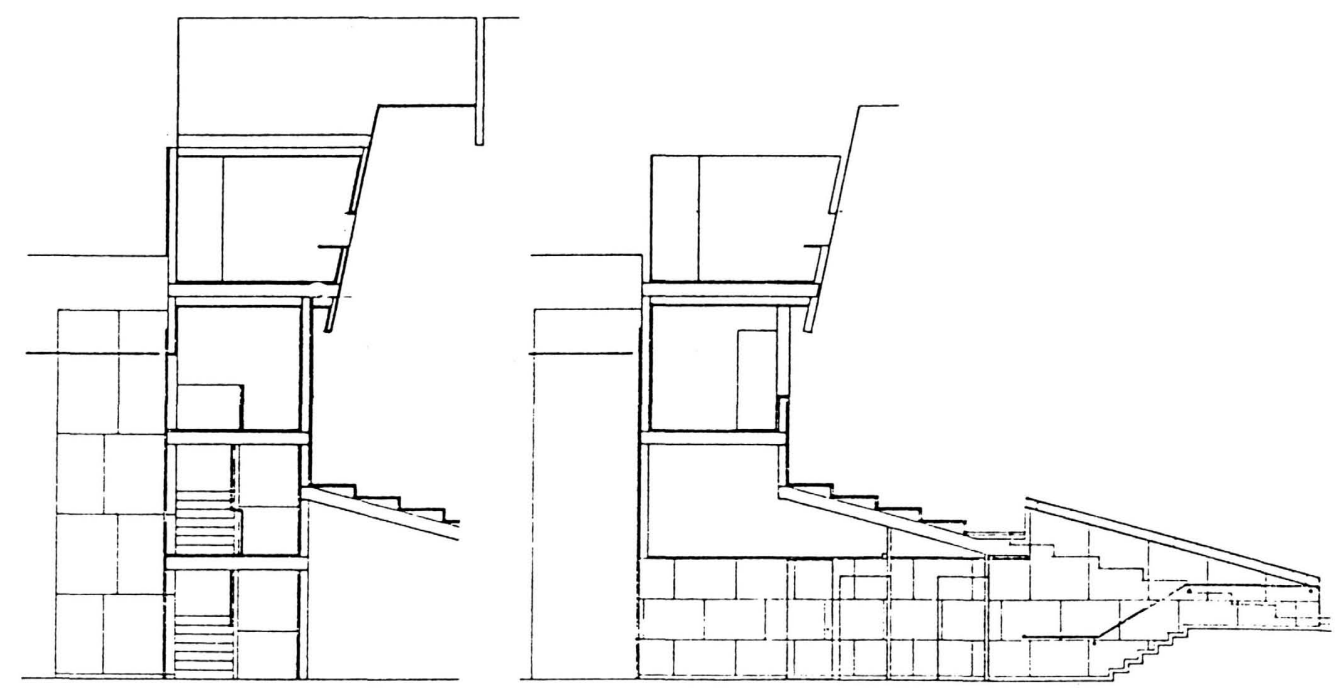

Secciones parciales de la sala principal.

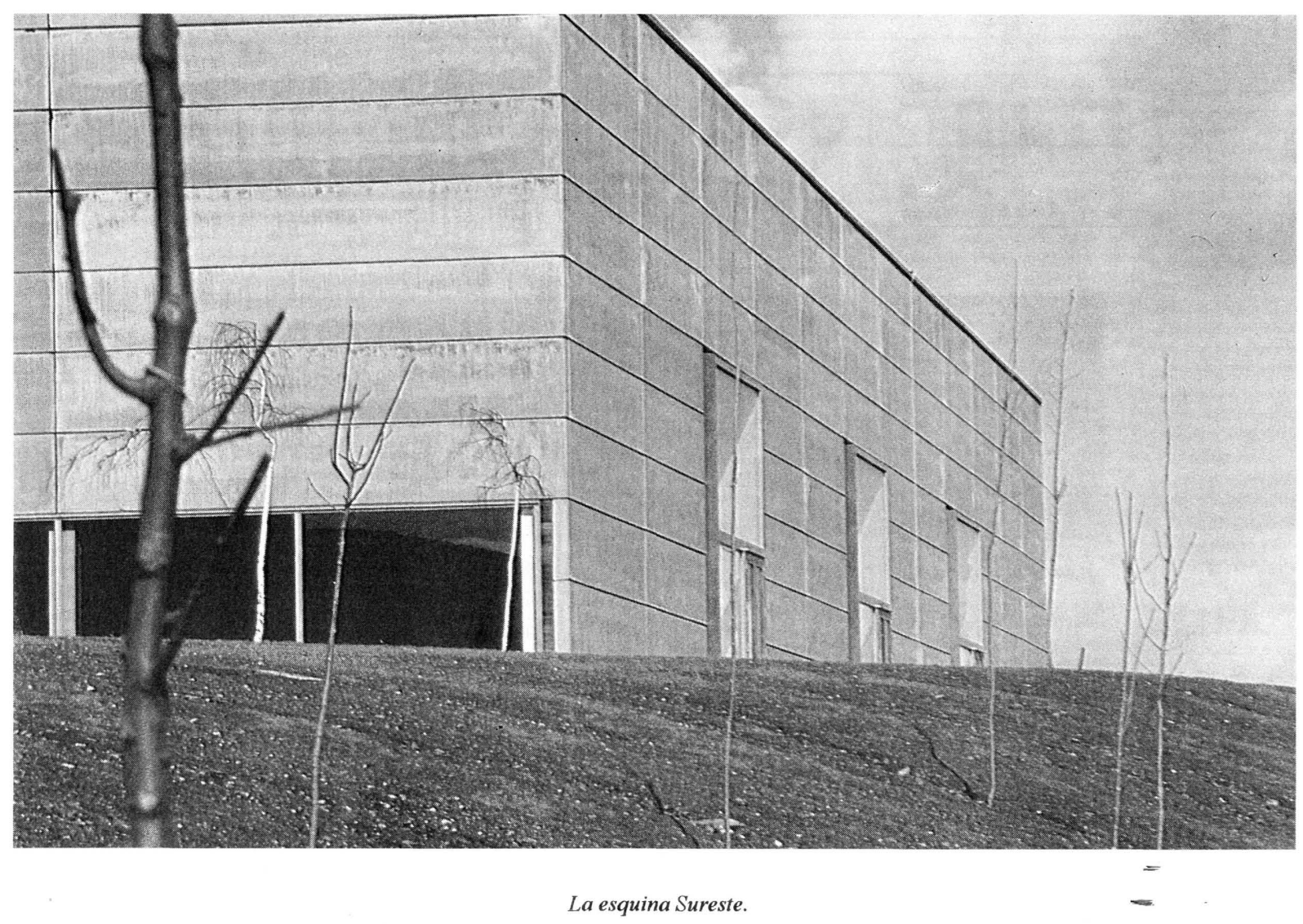

